\title{
Uma análise da transparência ativa nos sites ministeriais do Poder
}

\section{Executivo Federal brasileiro}

\author{
Luís Paulo Maia de Araújo \\ Universidade FUMEC, Programa de Pós-Graduação em Sistemas de Informação e \\ Gestão do Conhecimento, Belo Horizonte (MG) \\ mayaluis2012@outlook.com \\ Rodrigo Moreno Marques \\ Universidade FUMEC, Programa de Pós-Graduação em Sistemas de Informação e \\ Gestão do Conhecimento, Belo Horizonte (MG) \\ rodrigomorenomarques@yahoo.com.br
}

DOI: https://doi.org/10.26512/rici.v12.n2.2019.9236

Recebido/Recibido/Received: 2018-06-21

Aceitado/Aceptado/Accepted: 2019-01-02

Resumo: A transparência governamental no Brasil é norteada pela LAl - Lei de Acesso à Informação (Lei n. 12.527/2011) e pelo Decreto no 7.724/2012. No entanto, essas diretrizes não vêm sendo cumpridas integralmente pelos órgãos públicos brasileiros. Esse cenário ensejou a necessidade de se realizar uma pesquisa para avaliar se e como, atualmente, os sites dos órgãos do Poder Executivo Federal têm atendido os princípios de transparência ativa estabelecidos pela legislação. Nesse sentido, o problema que norteou a investigação pode ser sintetizado na seguinte questão: como os sites dos órgãos públicos que compõem o Poder Executivo Federal Brasileiro têm atendido às diretrizes de transparência ativa estabelecidas pela LAI e pelo Decreto $7.724 / 2012$ ? Com o objetivo de responder à questão colocada, realizou-se uma pesquisa documental que tomou como corpus os documentos eletrônicos publicados nos sites de alguns órgãos federais, no período de janeiro a dezembro de 2016. Confrontou-se o conteúdo dos sites com as diretrizes da legislação. Os resultados alcançados expõem relevantes descumprimentos das diretrizes de transparência ativa, como por exemplo, a ausência de divulgação de competências, horários de atendimento ao público, estrutura organizacional, dentre outros itens. Conclui-se que os sítios analisados necessitam passar por significativos aprimoramentos. Palavras-chave: Transparência governamental. Lei de Acesso à Informação. Poder Executivo Federal.

An analysis on the active transparency in websites of the Brazilian Federal Executive Power Abstract: Government transparency in Brazil is ruled by the LAI - Law on Access to Information (Law no 12,527/2011) and Decree no 7,724/2012. Nevertheless, this obligation has not been fully complied with by Brazilian public bodies. This scenario gave rise to a research aimed at investigating whether and how, currently, the websites of the Federal Executive Branch have complied with the principles of active transparency established by the legislation. In this sense, the problem that guided the investigation can be summarized in the following question: How have the websites of public agencies of the Brazilian Federal Executive Branch complied with the guidelines for active transparency established by LAI and Decree 7,724/2012? In order to answer the question, a documentary research was carried out, taking as a corpus the electronic documents published on some websites of these federal agencies, from January to December 
2016. The content of the sites was compared with the guidelines established by the law. The obtained results expose significant noncompliance with the guidelines for active transparency, such as the lack of disclosure of skills, hours of public service, organizational structure, among other items. The conclusion suggests the necessity of improving the analyzed sites.

Keywords: Governmental transparency. Law on access to public information. Federal Executive Power.

\section{Un análisis de la transparencia activa en los sitios ministeriales del poder ejecutivo federal brasileño}

Resumen: La transparencia gubernamental en el Brasil es guiada por la Ley de acceso a la información (Ley no 12.527/ 011) y por el Decreto no 7.724/2012. Sin embargo, esa obligación no viene siendo cumplida íntegramente por los organismos públicos brasileños. Este escenario propició la necesidad de realizar una investigación para evaluar si y cómo actualmente los sitios de los órganos del Poder Ejecutivo Federal han cumplido los principios de transparencia activa establecidos por la legislación. En este sentido, el problema que orientó la investigación ahora relatada puede ser sintetizado en la siguiente pregunta: ¿cómo los sitios de los órganos públicos que componen el Poder Ejecutivo Federal Brasileño han cumplido las directrices de transparencia activa establecidas por LAl y por el Decreto 7.724/2012? Para responder a la pregunta planteada, se realizó una investigación documental que tomó como corpus los documentos electrónicos publicados en algunos sitios de esos órganos federales, en el período de enero a diciembre de 2016. Se comparó el contenido de los sitios con las directrices establecidas en la legislación. Los resultados alcanzados revelan incumplimientos considerables de las directrices de transparencia activa como, por ejemplo, la ausencia de divulgación de competencias, horarios de atención al público, estructura organizacional, entre otros ítems. Se concluye que los sitios analizados necesitan pasar por significativas mejoras.

Palabras clave: Transparencia gubernamental. Ley de acceso a la información. Poder Ejecutivo Federal.

\section{Introdução}

A Lei n. 12.527 de 18 de novembro de 2011, conhecida como Lei de Acesso à Informação (LAI), e o Decreto n. 7.724 de 16 de maio de 2012, que regulamentou a LAI na esfera federal, representam um grande avanço na história das iniciativas para instituir e ampliar o acesso à informação pública no Brasil (SÁ; MALIN, 2012).

Os princípios da transparência ativa e da transparência passiva são elementos centrais tanto da LAI quando do referido decreto federal. Ambas as modalidades de transparência são obrigatórias para todos os órgãos e entidades públicas federais, estaduais, municipais e distritais, dos poderes Executivo, Legislativo e Judiciário, além de toda a administração pública, sendo facultativo o seu cumprimento nos casos dos municípios cuja população seja inferior a dez mil habitantes.

De acordo com o princípio da transparência ativa, esses órgãos têm o dever de informar a sociedade de forma proativa e espontânea, sobre sua gestão e seus atos, por meio da divulgação de informações públicas por eles produzidas ou custodiadas. Já o princípio da 
transparência passiva está voltado para o fornecimento de informações públicas mediante a solicitação de um cidadão, por meio de Sistemas de Informação ao Cidadão (SIC).

Os SIC possuem a função de atender e orientar os cidadãos sobre pedidos de informação, receber e registrar os pedidos de acesso, devolver as respostas aos solicitantes e informar sobre a tramitação de documentos e requerimentos de acesso à informação. Os chamados e-SIC são aqueles que proveem seus serviços via web. Esses sistemas devem permitir o encaminhamento de solicitações de acesso à informação para diversos órgãos e entidades públicas, sejam elas protocoladas por pessoas físicas ou jurídicas, além de possibilitar que o solicitante acompanhe o status de suas solicitações, consulte respostas recebidas, protocole recursos, reclamações, dentre outras opções.

Passados mais de seis anos após sua sanção, as diretrizes de transparência ativa e passiva estabelecidas pela LAI não estão sendo cumpridas em sua totalidade, pelos órgãos e entidades públicas. Diferentes pesquisas têm se debruçado sobre essa realidade e buscado acompanhar as evoluções dessa problemática em diferentes órgãos das três esferas do poder público (ARTIGO 19; 2013, 2014, 2015, 2017; CAVALCANTI; DAMASCENO; NETO, 2013; GOMES, 2016; GOMES; MARQUES; KERR PINHEIRO, 2016; JARDIM; MIRANDA, 2015; MENDES, 2014; SANTOS; NAVARRO, 2016; NASCIMENTO SILVA; KERR PINHEIRO, 2015; VENTURA; FELL, 2012; VIEIRA, 2013).

Esse cenário ensejou a necessidade de se realizar uma pesquisa documental para avaliar se e como, atualmente, os sites dos órgãos do Poder Executivo Federal cumprem os princípios de transparência ativa estabelecidos pela LAl e pelo Decreto n. 7.724/2012. Nesse sentido, o problema que norteou este trabalho pode ser sintetizado na seguinte questão: como os sites dos órgãos públicos que compõem o Poder Executivo Federal Brasileiro têm atendido às diretrizes de transparência ativa estabelecidas pela LAl e pelo Decreto n. 7.724/2012 ${ }^{1}$

Nesse sentido, este artigo relata pesquisa por meio da qual analisou-se como se dá o cumprimento das diretrizes de transparência ativa estabelecidas pela Lei de Acesso à Informação e pelo Decreto n. 7.724, por parte de órgãos públicos do Poder Executivo Federal Brasileiro. Apresenta-se resultados de uma análise feita nos sites de alguns órgãos públicos do Poder Executivo Federal Brasileiro em relação a transparência ativa, abrangendo o período de janeiro a dezembro de 2016. Os resultados alcançados pela investigação apontam descumprimentos das diretrizes de transparência ativa e a necessidade de realização de diversas melhorias nos sites dos órgãos pesquisados. Informações básicas e obrigatórias não foram encontradas nos

\footnotetext{
${ }^{1} \mathrm{O}$ conceito de órgão adotado na presente pesquisa e o recorte realizado na etapa empírica da mesma são discutidos na quarta seção do artigo (Metodologia).
} 
sites de alguns órgãos, como por exemplo, suas competências, horários de atendimento ao público, estrutura organizacional, dentre outros itens.

O artigo está estruturado em seis seções. Após essa introdução, são abordados os princípios da transparência ativa segundo a LAl e o Decreto 7.724/2012. Na terceira seção são discutidas algumas pesquisas que têm investigado e como os sites dos órgãos públicos têm atendido essas diretrizes legais. Na seção seguinte, apresenta-se a metodologia utilizada na investigação realizada nos sites dos órgãos do poder executivo federal. Em seguida, são apresentados e analisados os resultados alcançados. Na seção final, são sintetizadas as principais conclusões da pesquisa.

\title{
2 Transparência ativa
}

O principal aspecto da transparência ativa é o dever de órgãos e entidades públicas, em todos os níveis e poderes, de divulgarem, de forma proativa e voluntária, informações de interesse público por eles produzidas ou custodiadas, em local físico de fácil acesso e em seus sites oficiais por meio da Internet. Nesse sentido, Zuccolotto, Teixeira e Riccio afirmam que:

\begin{abstract}
A Transparência ativa consiste na difusão periódica e sistematizada de informações sobre a gestão estatal. Resulta de ações voluntárias dos gestores públicos ou de obrigações legais impostas aos órgãos do Estado, determinando que sejam publicadas informações necessárias e suficientes para que a sociedade possa avaliar o desempenho governamental (ZUCCOLOTTO; TEIXEIRA; RICCIO, 2015, p. 148).
\end{abstract}

A transparência ativa gera benefícios tanto para o cidadão, quanto para a administração pública. Para o cidadão, ela busca dar maior transparência aos gastos públicos, ampliando assim a possibilidade de alcançar outros direitos. Para a administração pública, a transparência ativa tende a gerar economia de tempo e recursos. Conforme explica Gruman (2012, p. 102), "a transparência das informações está diretamente relacionada ao aprimoramento dos mecanismos de alocação de verbas públicas e à qualidade dos gastos governamentais". Para Yazigi (1999), a transparência ativa é uma ferramenta essencial no processo de modernização do Estado, pois elucida os compromissos do governo para que possam ser reivindicados como direitos sociais posteriormente. Contudo, Cepik (2000, p. 8) defende a ideia de que não é suficiente que as informações sejam disponibilizadas, uma vez que muitas dessas informações podem ser "de péssima qualidade para as finalidades de orientação do poder decisório tanto participativo como intragovernamental".

Merece destaque o fato de que, apesar da LAI estabelecer diretrizes claras para transparência ativa e passiva, foi o Decreto Federal n. 7.724/2012 que, pela primeira vez na história da legislação brasileira, explicitou os termos "transparência ativa" e "transparência 
passiva". No entanto, ainda que o termo 'transparência ativa' não conste na LAI, esse princípio se faz presente no artigo 8 o dessa lei. $O$ artigo dispõe sobre o dever dos órgãos e entidades públicas de fornecer informações de interesse público em local de fácil acesso ao cidadão, sem a necessidade de requerimentos pelo mesmo. Nos termos do artigo $8^{\circ}$ da lei,

É dever dos órgãos e entidades públicas promover, independentemente de requerimentos, a divulgação em local de fácil acesso, no âmbito de suas competências, de informações de interesse coletivo ou geral por eles produzidas ou custodiadas (BRASIL, 2011).

Dentre essas informações, deve ser divulgado no mínimo:

I. Registro das competências e estrutura organizacional, endereços e telefones das respectivas unidades e horários de atendimento ao público;

II. Registros de quaisquer repasses ou transferências de recursos financeiros; III. Registros das despesas;

IV. Informações concernentes a procedimentos licitatórios, inclusive os respectivos editais e resultados, bem como a todos os contratos celebrados; V. Dados gerais para o acompanhamento de programas, ações, projetos e obras de órgãos e entidades; e

VI. Respostas a perguntas mais frequentes da sociedade (BRASIL, 2011).

O artigo 8 o trata também da forma de disponibilização das informações públicas. Os órgãos devem utilizar todos os meios legítimos ao seu alcance para divulgarem as mesmas, sendo a disponibilização por meio eletrônico (sites oficiais na Internet) de caráter obrigatório. No mesmo artigo da LAl, são especificados oito requisitos de cumprimento indispensável, voltados para os sites oficiais desses órgãos, com a finalidade de proporcionar uma melhor experiência de acesso às informações públicas.

O primeiro requisito determina que todo site deverá possuir uma ferramenta de pesquisa de conteúdo. Essa ferramenta é importante para ajudar os usuários a encontrar as informações que procuram com maior agilidade e exatidão. As informações devem estar expostas de forma clara, transparente, objetiva e em uma linguagem que facilite a compreensão. Devem ser evitados jargões técnicos e outros tipos de palavras que requeiram maior nível de instrução ou formação específica para sua compreensão. O segundo requisito busca garantir a variedade de formatos de arquivos digitais e sugere adoção de formatos de arquivos abertos e não proprietários, com a finalidade de facilitar a análise das informações. 0 terceiro requisito visa possibilitar o acesso automatizado por sistemas externos, por meio de formatos abertos, estruturados e que sejam legíveis por máquinas. O quarto requisito, por sua vez, postula que todo órgão público deverá divulgar de forma detalhada todos os formatos utilizados no processo de estruturação da informação. $O$ quinto requisito dispõe sobre a garantia da autenticidade e integridade das informações públicas disponibilizadas por esses órgãos. 0 sexto requisito determina que os órgãos e entidades públicas deverão manter as informações 
atualizadas e disponíveis para pronto acesso da população. Segundo o sétimo requisito, deverá ser indicado o local e as instruções necessárias para que o cidadão entre em contato com o órgão responsável pelo site. Essa comunicação poderá ser feita por meio eletrônico (e-mail ou chat) ou por contato telefônico. Por fim, o oitavo requisito está voltado para a garantia de acessibilidade às informações públicas por parte das pessoas com deficiência. A divulgação por meio eletrônico (Internet) dos requisitos mínimos já citados é facultativa para municípios com menos de 10.000 (dez mil) habitantes, mas esses ficam obrigados a divulgar as informações relativas à execução orçamentária e financeira de seus municípios (BRASIL, 2011).

O artigo 9으 da LAl estabelece que o acesso à informação pública deverá ser assegurado por meio do Serviço de Informação do Cidadão. O SIC deve ser criado e implantado em local e condições adequadas para: atender o orientar o público em relação ao acesso às informações, prover informações sobre a tramitação de documentos, protocolizar documentos e requerimentos de acesso às informações públicas. Adicionalmente, o art. 9o estabelece que o acesso à informação também deve ser assegurado por meio da "realização de audiências ou consultas públicas, incentivo à participação popular ou a outras formas de divulgação" (BRASIL, 2011).

A transparência ativa relativa às informações classificadas, desclassificadas e relatórios de pedidos de acesso à informação é objeto do art. 30 da LAl e do art. 45 Decreto Federal n. 7.724/2012. Segundo a legislação, os órgãos públicos devem fornecer de forma espontânea o rol das informações que tenham sido desclassificadas nos últimos doze meses, o rol de documentos classificados em cada grau de sigilo (com identificação para referência futura), e o relatório estatístico contendo a quantidade de pedidos de informação recebidos, atendidos e indeferidos, bem como informações genéricas sobre os solicitantes (BRASIL, 2011, 2012).

O Decreto n. 7.724/2012 detalha alguns requisitos estabelecidos pela Lei 12.527/2011. Em relação à transparência ativa, o decreto estabelece, em seu Art.7ํㅡ, os itens obrigatórios a serem divulgados nos sítios dos órgãos federais:

I. Banner na página inicial (...);

II. Barra de identidade do Governo federal, contendo ferramenta de redirecionamento de página para o Portal Brasil e para o sítio principal sobre a Lei no 12.527, de 2011.

(...)

I. Estrutura organizacional, competências, legislação aplicável, principais cargos e seus ocupantes, endereço e telefones das unidades, horários de atendimento ao público;

II. Programas, projetos, ações, obras e atividades, com indicação da unidade responsável, principais metas e resultados e, quando existentes, indicadores de resultado e impacto;

III. Repasses ou transferências de recursos financeiros;

IV. Execução orçamentária e financeira detalhada; 
V. Licitações realizadas e em andamento, com editais, anexos e resultados, além dos contratos firmados e notas de empenho emitidas;

VI. Remuneração e subsídio recebidos por ocupante de cargo, posto, graduação, função e emprego público, incluindo auxílios, ajudas de custo, jetons e quaisquer outras vantagens pecuniárias, bem como proventos de aposentadoria e pensões daqueles que estiverem na ativa, de maneira individualizada, conforme ato do Ministério do Planejamento, Orçamento e Gestão;

VII. Respostas a perguntas mais frequentes da sociedade; (Redação dada pelo Decreto $n$ o 8.408, de 2015)

VIII. Contato da autoridade de monitoramento, designada nos termos do art. 40 da Lei no 12.527, de 2011, e telefone e correio eletrônico do Serviço de Informações ao Cidadão - SIC; e (Redação dada pelo Decreto no 8.408, de 2015)

IX. Programas financiados pelo Fundo de Amparo ao Trabalhador - FAT. (BRASIL, 2012).

O artigo 45ำ do decreto n. 7.724/2012 afirma que, a autoridade máxima de cada órgão ou entidade deve publicar anualmente até o primeiro dia de junho, em seu site, o rol das informações desclassificadas nos últimos doze meses e o rol das informações classificadas em cada grau de sigilo, que deverá conter o código de indexação de documento, a categoria na qual se enquadra a informação, a indicação de dispositivo legal que fundamenta a classificação, a data de produção, data de classificação e prazo de classificação. Ainda segundo o mesmo artigo, os órgãos deverão publicar um relatório estatístico com a quantidade de pedidos de acesso à informação recebidos, atendidos e indeferidos, e as informações estatísticas agregadas dos requerentes (BRASIL, 2012).

Diversas pesquisas têm procurado avaliar como os órgãos públicos brasileiros têm atendido as diretrizes determinadas pela LAl e pelo Decreto n. 7.724/2012, conforme discutese na sessão a seguir.

\section{Pesquisas correlatas}

Ventura e Fell (2012) realizaram uma pesquisa relativa ao cumprimento da LAl e os reflexos de sua aplicação pelas instituições de ensino superior da região Nordeste do país. Os resultados alcançados podem ser considerados alarmantes pois nenhuma das instituições pesquisadas conseguiu disponibilizar todas as informações de divulgação obrigatória. Os autores afirmam que as instituições possuem uma certa resistência ao fornecimento de informações públicas.

Vieira (2013) pesquisou os efeitos da LAI nas compras públicas. A partir da sua pesquisa, a autora conclui que ainda existem no país diversos desafios a serem superados, sendo o maior deles a cultura do sigilo que predomina nos órgãos da administração pública no Brasil. Em relação ao predomínio da cultura de sigilo em detrimento da cultura de transparência nos órgãos 
públicos brasileiros, Gomes (2016) e Gomes, Marques e Kerr Pinheiro (2016) também concordam com Vieira (2013).

Cavalcanti, Damasceno e Neto (2013) investigaram a aplicação da lei de acesso à informação em autarquias federais. Na pesquisa, a amostra foi composta por 30 autarquias federais, selecionadas de forma aleatória no site da Advocacia Geral da União (AGU). Foi realizada uma listagem de verificação composta por 19 perguntas relacionadas aos artigos 60 ao 10 da LAl, que dispõem acerca das garantias ao direito de acesso às informações públicas, da divulgação proativa de informações e dos pedidos de acesso às informações. A amostra da pesquisa incluiu autarquias vinculadas a vários ministérios, sendo que $60 \%$ eram universidades e institutos federais de ensino associados ao Ministério da Educação, 6,5\% eram instituições ligadas ao Ministério da Saúde, 6,5\% eram ligadas ao Ministério de Minas e Energia, e 27\% se dividiam entre os Ministérios da Cultura, Meio Ambiente, Previdência Social, Transportes, Justiça, Relações Exteriores, Turismo e Integração Nacional, cada um representando cerca de $3 \%$ da amostra total. Os autores verificaram que as 30 autarquias seguiram de forma mediana as determinações da LAI. Contudo, também foi identificado que, em relação a algumas diretrizes da lei, o descumprimento pelos órgãos públicos pesquisados estava acima de $90 \%$. Os autores recomendam que seja replicado o instrumento de pesquisa nos Estados e Municípios, e que seja verificada a evolução do atendimento da lei nas autarquias pesquisadas, para fins de acompanhamento desse progresso. Recomendam, ainda, orientar as autarquias, órgãos e entidades federais a realizarem pesquisas de satisfação junto aos seus usuários, com a finalidade de avaliar a facilidade de uso das ferramentas disponibilizadas para acesso à informação e identificar possíveis melhorias nas transparências ativa e passiva.

A organização não governamental Artigo 19 realizou a sua primeira análise da LAI quando ele completou um ano de vigência (ARTIGO 19, 2013). Nessa pesquisa, foram submetidos mais de 140 pedidos de acesso à informação para diferentes órgãos públicos da esfera federal, estadual e municipal. Os resultados revelados se mostraram preocupantes, pois menos da metade das respostas recebidas contemplaram integralmente o que era esperado, e cerca de 32\% dos órgãos pesquisados não responderam, mesmo após o prazo legal de 20 dias corridos após a solicitação. A ONG concluiu que "a regulamentação do direito à informação não é garantia de que esse direito seja respeitado. Além do comprometimento institucional da Administração Pública, cabe à sociedade civil e a cada indivíduo participar desse processo" (ARTIGO 19, 2013, p. 4).

Entre setembro e dezembro de 2013, a ONG Artigo 19 (2014) analisou a implementação da Lei de Acesso à Informação brasileira em 51 órgãos públicos, sendo 38 órgãos do Executivo, 
11 órgãos de Justiça e 2 órgãos Legislativos. A pesquisa investigou os princípios da transparência ativa e da transparência passiva. Foram enviados 474 pedidos de informação para esses órgãos públicos a fim de analisar o cumprimento das diretrizes de transparência passiva. A transparência ativa, por sua vez, foi analisada de acordo com seis preceitos básicos da LAl, que foram divididos em 11 subitens. Essa pesquisa mostrou que, 98,9\% dos pedidos realizados foram respondidos pelos órgãos que compunham o Poder Executivo Federal à época, enquanto apenas $1,1 \%$ das solicitações não foram respondidas. Contudo apenas $64,9 \%$ dos pedidos foram atendidos com concessão integral de acesso, enquanto 30,3\% das solicitações resultaram em concessão parcial de acesso, 1,7\% delas corresponderam às informações que o órgão afirmou não possuir e $2 \%$ foram respondidas com negativa de acesso. A partir desses resultados, a ONG Artigo 19 chegou à conclusão de que "poucos meses antes da LAl completar dois anos de vigência, foram constatados avanços e dificuldades na implementação no âmbito federal" (ARTIGO 19, 2013, p. 10).

No período de novembro de 2014 a março de 2015, a ONG Artigo 19 (2015) investigou mais uma vez a evolução da implementação da LAl em 51 órgãos públicos, em relação às transparências ativa e passiva. Para avaliar a transparência passiva, foram enviadas 255 consultas para esses órgãos públicos. A transparência ativa foi analisada de acordo com os seis preceitos básicos da LAI. No Poder Executivo Federal Brasileiro, 98,9\% das solicitações foram atendidas. Contudo, a notou-se a diferença na proporção das formas de atendimento: $73,2 \%$ das solicitações resultaram em acesso integralmente concedido, ou seja, experimentaram um aumento de $8,3 \%$, o que pode ser considerado uma melhora significativa. Os acessos parciais corresponderam a $23,2 \%$, o que representou um aumento de $7,1 \%$ em relação à média constatada no ano anterior. Outras melhoras também foram detectadas: as situações em que os órgãos afirmaram não possuir a informação ou negaram o acesso a ela passaram a representar, respectivamente, $1,1 \%$ e $1,6 \%$ das solicitações atendidas. A ONG chegou à conclusão de que nenhum dos órgãos públicos pesquisados cumpriu integralmente os requisitos mínimos estipulados pela LAl e que diversas melhorias deveriam ser feiras nos mesmos, visando garantir o cumprimento integral da lei.

Mendes (2014) avaliou como se dava a aplicação da LAI nas agências reguladoras brasileiras. $\mathrm{O}$ autor constatou que, após dois anos de vigência da lei, os resultados indicavam que a aderência às diretrizes legais ainda era primária e necessitava de diversas melhorias.

A pesquisa realizada por Nascimento Silva e Kerr Pinheiro (2015), objetivou a identificação das categorias informacionais dos dados governamentais abertos disponibilizados por meio da transparência ativa pelas universidades públicas federais do Brasil em seus 
respectivos sites, abrangendo o primeiro triênio de implantação da LAI. Nessa investigação, avaliou-se a adequação dessas universidades ao rol mínimo estabelecido pelo artigo 8 o da LAl. Foi realizada pesquisa documental, que tomou como corpus os documentos eletrônicos publicados nos sites dessas universidades federais. No total, foram selecionadas 55 universidades, mas somente 45 foram analisadas (81,82\%), pois, em 10 instituições, a página referente ao acesso à informação não foi localizada no site oficial da universidade, a página estava indisponível ou redirecionava o acesso para um dos portais oficiais de transparência, não contendo quaisquer informações específicas a respeito da instituição. Ao final da pesquisa, concluiu-se que ainda era baixo o percentual de adequação ao rol mínimo de informações que deveriam ser divulgadas de acordo com o art. 8 da LAI. Segundo os resultados da pesquisa, $37,27 \%$ das universidades pesquisadas cumpriam integralmente esses requisitos, sendo que 18,18\% não disponibilizavam nenhuma das informações exigidas pela LAI (NASCIMENTO SILVA; KERR PINHEIRO, 2015).

Jardim e Miranda (2015) realizaram um estudo sobre a implantação da LAl nas universidades federais do Estado do Rio de Janeiro. Foram analisados aspectos arquivísticos do processo de implementação da LAI, entre maio de 2012 e maio de 2014. Concluiu-se que a transparência passiva é mais bem desenvolvida do que a transparência ativa, sendo que a articulação entre os Serviços Arquivísticos e os Serviços de Informação ao Cidadão era muito limitada nas instituições pesquisadas.

Santos e Navarro (2016) analisaram o cumprimento da LAI nos sites das Secretarias da Fazenda dos Estados brasileiros e do Distrito Federal. O objetivo dessa investigação realizada assemelha-se ao do presente trabalho, uma vez que os autores utilizaram o rol mínimo de informações que a LAl estabelece para analisar a transparência ativa nos sites pesquisados. As diferenças entre a pesquisa de Santos e Navarro e a presente pesquisa residem principalmente na amostra selecionada e na quantidade de itens analisados. Na pesquisa que o presente artigo relata, buscou-se analisar esses itens de uma forma mais detalhada e individualizada. Segundo a conclusão de Santos e Navarro (2016), poucos requisitos foram cumpridos integralmente por todos os órgãos pesquisados.

A ONG Artigo 19 (2017) publicou o seu mais novo relatório relacionado a LAl, denominado Os 5 anos da Lei de Acesso à Informação uma análise de casos de transparência. Esse relatório mostra os avanços e principais desafios na implementação da LAI pelos órgãos públicos brasileiros. Dentre os avanços, podem ser citados: um progresso considerável no volume de informações acessíveis à população e a quantidade de cidades e estados em que a aplicação da LAl avançou. Já em relação aos desafios encontrados para a plena implementação 
constatou-se principalmente a baixa divulgação, por meio de transparência ativa, de informações de qualidade que viabilizem a participação popular efetiva.

A presente pesquisa adotou objetivo similar. No entanto, podemos destacar algumas diferenças entre elas: (i) o universo da presente pesquisa está restrito ao Poder Executivo Federal; (ii) o recorte temporal é diferente; e (iii) os critérios adotados para analisar a transparência ativa e passiva foram distintos.

\section{Metodologia}

A investigação é de natureza aplicada, sua abordagem é qualitativa e sua finalidade é descritiva. Quanto aos procedimentos, foi realizada pesquisa bibliográfica e pesquisa documental. Para realização da pesquisa documental, sites de órgãos governamentais investigados foram tomados como documentos eletrônicos, ou seja, fonte de informação primária. Os conteúdos disponibilizados nesses sites, no período de janeiro a dezembro de 2016, foram analisados para avaliação do cumprimento das diretrizes de transparência governamental.

Inicialmente, mostra-se importante explicitar o conceito de órgão adotado na presente investigação. Segundo Meireles (2005), órgão público é o centro de competências instituído para o desempenho de funções estatais, que são levadas a cabo por meio de agentes que ocupam cargos públicos, conforme estabelece o art. 37 da Constituição Federativa.

$\mathrm{O}$ autor explica que, quanto à posição estatal, são considerados órgãos independentes aqueles que

são constitucionais, representativos dos Poderes Legislativo, Executivo e
Judiciário, sem qualquer subordinação hierárquica ou funcional, só sujeitos
aos controles constitucionais de um Poder pelo outro; exercem
precipuamente as funções outorgadas diretamente pela Constituição,
desempenhadas por agentes políticos, segundo normas especiais e
regimentais (MEIRELLES, 2005, p. 63).

São exemplos de órgãos independentes a chefia do Poder Executivo, o Congresso Nacional e os Tribunais de Justiça. Já os órgãos autônomos são os que estão localizados no alto da estrutura organizacional da administração pública, mas são subordinados aos órgãos independentes. Possuem ampla autonomia administrativa, financeira e técnica. Estão voltados para as ações de planejamento, supervisão, coordenação e controle de atividades, a exemplo dos Ministérios, Secretarias Estaduais e Municipais.

O conceito de órgão adotado nesta pesquisa se baliza no disposto do art. $37 \mathrm{da}$ Constituição Federal. Contudo, por motivos de viabilidade técnica da pesquisa, como recorte da investigação empírica, optou-se pela análise dos sites dos Ministérios e da Presidência da 
República, sem considerar os sites dos demais órgãos ou entidades que compõem suas estruturas, como por exemplo suas secretarias. Na pesquisa que o presente artigo relata, os sites de vinte e três órgãos que compõem atualmente o Poder Executivo Federal Brasileiro foram analisados em relação ao cumprimento das diretrizes legais de transparência ativa e passiva. Para análise da transparência ativa, a investigação não se limitou somente ao rol mínimo de informações exigidos pelo art. 8ㅇ da LAl, mas incluiu também os artigos 9o e 30으 da LAl e os artigos 7으 e 45으 do Decreto n. 7.724/2012. Para análise da transparência passiva empregou-se

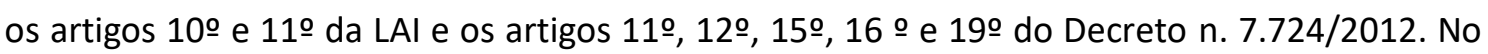
presente artigo, são apresentados apenas os resultados relativos à análise das diretrizes de transparência ativa. Foram analisados os sites dos seguintes órgãos:

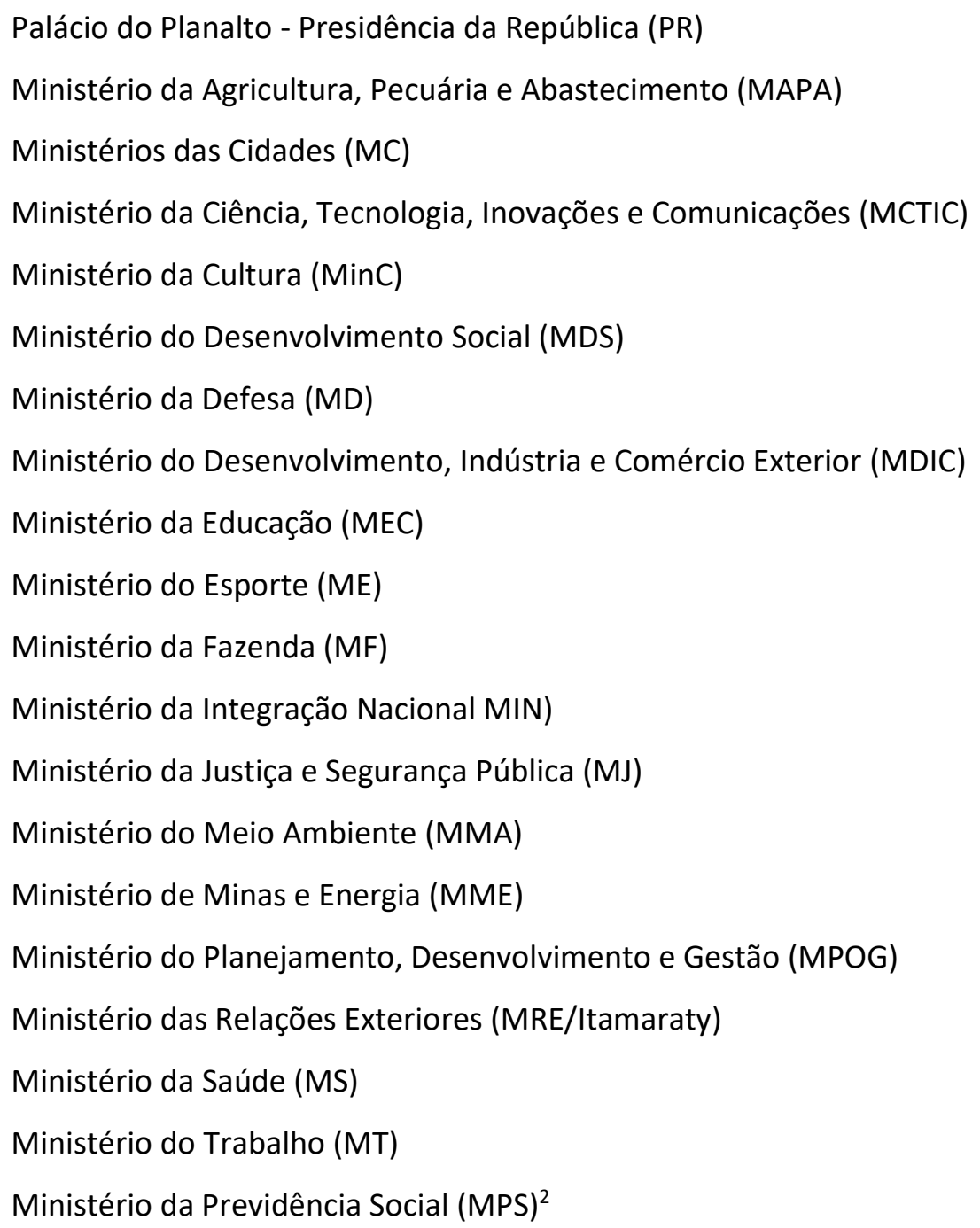

\footnotetext{
${ }^{2}$ Em 13 de março de 2017, por meio do Decreto no 9.003 (BRASIL, 2017), houve a extinção do Ministério da Previdência Social, que se tornou uma secretaria vinculada ao Ministério da Fazenda. Neste trabalho, a Previdência Social foi tratada como ministério pois a mesma só se tornou secretaria após a coleta dos dados da pesquisa. O mesmo decreto alterou a estrutura de alguns dos órgãos pesquisados e, portanto, foi necessário fazer algumas adequações ao longo do trabalho, como a mudança de nome desses órgãos.
} 
Ministério da Transparência e Controladoria-Geral da União (CGU)

Ministério dos Transportes, Portos e Aviação Civil (MTPA)

Ministério do Turismo (MTur)

Para análise dos dados, três tipos de classificação foram adotados na pesquisa:

Requisito cumprido integralmente: o órgão disponibilizou a informação em seu próprio site, o link de acesso está em perfeito funcionamento, e o acesso à informação se dá em até dois cliques a partir da página principal.

Requisito cumprido parcialmente: o órgão disponibilizou a informação de forma incompleta em seu próprio site e/ou alguns links de acesso não funcionam perfeitamente.

Requisito descumprido: o órgão não disponibilizou a informação ou a mesma se encontrava indisponível no site devido a problemas técnicos, o link de acesso não funciona ou redireciona para alguma informação diferente da pesquisada, ou o acesso à informação exige mais de dois cliques a partir da página principal.

\section{Resultados e discussões dos resultados}

A pesquisa revelou que os seguintes requisitos foram cumpridos parcialmente pelos sites dos órgãos do poder executivo federal.

Banner de identificação da seção "Acesso à Informação" na página inicial: a divulgação desse requisito foi cumprida por 22 dos 23 órgãos pesquisados. Não foi encontrado o referido banner na página inicial do Ministério da Saúde. Vale salientar que a estrutura desse site é bastante diferente do padrão utilizado pelos demais sites pesquisados. Outra característica observada nesse requisito foi a ausência da logomarca que leva ao Portal Brasil em 4 dos 23 sites pesquisados. Adicionalmente, notou-se que o Ministério da Cultura e o Ministério do Desenvolvimento social utilizam cores e designs diferentes do padrão utilizado pelos demais órgãos.

Estrutura organizacional: a divulgação desse requisito foi cumprida por 21 dos 23 órgãos pesquisados). A estrutura organizacional não foi encontrada nos sites oficiais do Ministério dos Esportes e do Ministério da Previdência Social. Outro aspecto observado foi que alguns dos órgãos pesquisados substituem a nomenclatura 'Estrutura Organizacional' por 'Organograma' ou 'Organogramas'. Apesar dessa divergência na nomenclatura não ser um grande problema, recomenda-se que os órgãos padronizem a terminologia adotada.

Competências: a divulgação desse requisito foi cumprida por 21 dos 23 órgãos pesquisados. Ele não foi encontrado nos sites oficiais do Ministério da Agricultura Pecuária e 
Abastecimento e do Ministério da Previdência Social. Nesses, observa-se a ausência de um link específico que leve a tal informação, como ocorre nos sites dos demais órgãos. Já no caso do Ministério do Desenvolvimento Social, Ministério do Planejamento, Desenvolvimento e Gestão e o Ministério do Turismo, a informação existe, porém não se relaciona a um link específico. Para esses órgãos recomenda-se a criação do link, de modo a facilitar a consulta pelos cidadãos. Nesse requisito, observou-se que o site do Palácio do Planalto - Presidência da República, redireciona tal informação para os sites das secretarias que o compõem.

Principais cargos e seus ocupantes: a divulgação desse requisito foi cumprida por 22 dos 23 órgãos pesquisados. No site do Ministério da Previdência Social, o link se encontrava inativo. O site do Palácio do Planalto redireciona tal requisito para os sites de suas secretarias.

Endereço das unidades: apesar de esse ser um requisito que poderia ser facilmente cumprido pelos órgãos públicos, nem todos o cumpriram. No site do Ministério da Fazenda, a página que continha tais informações era incompleta, pois faltavam os endereços de algumas unidades. Já no caso do Ministério da Defesa, apenas foi encontrado o endereço do SIC. O site do Palácio do Planalto redireciona tal requisito para os sites de suas secretarias.

Telefones das unidades: esse requisito também foi cumprido parcialmente pelo Ministério da Fazenda. Notou-se a falta de alguns dados relativos aos telefones das unidades. 0 Ministério da Defesa, o Ministério da Indústria, Comércio Exterior e Serviços e o Ministério da Transparência e Controladoria-Geral da União fornecem apenas o telefone de seus respectivos SIC.

Horários de atendimento ao público: esse requisito foi descumprido pelo Palácio do Planalto. O Ministério da Fazenda, por sua vez, cumpriu esse requisito parcialmente. Notou-se a falta de alguns dados relativos aos horários de atendimento. Já o Ministério da Agricultura, Pecuária e Abastecimento, o Ministério da Ciência, Tecnologia, Inovações e Comunicações, o Ministério da Defesa e o Ministério da Transparência e Controladoria-Geral da União, fornecem apenas os horários de atendimento ao público de seus SIC.

Programas, projetos, ações, obras e atividades, com indicação da unidade responsável, principais metas e resultados e, indicadores de resultado e impacto: esse requisito foi cumprido por 22 dos 23 órgãos pesquisados. Considerou-se que o Ministério do Planejamento, Desenvolvimento e Gestão cumpriu parcialmente o requisito pois alguns links eram inexistentes ou não estavam ativos. No caso do Ministério do Trabalho, percebeu-se a necessidade de que o órgão utilize o link padronizado como os demais órgãos do Poder Executivo Federal já fazem. Já no caso do Ministério de Minas e Energia, o site adota uma nomenclatura diferente do padrão 
utilizado pelos demais órgãos. O site do Palácio do Planalto redireciona tal requisito para os sites de suas secretarias.

Repasses ou transferências de recursos financeiros: esse requisito foi cumprido por 21 dos 23 órgãos pesquisados. No caso do Ministério da Transparência e Controladoria-Geral da União, o link que levava à tal informação se encontrava inativo, não sendo possível seu acesso. Já o Ministério da Saúde apresentava um link inativo e as demais informações se encontravam bastante desorganizadas, o que dificulta a sua compreensão. Nos demais órgãos, observou-se que as informações referentes a repasses ou transferências de recursos financeiros eram disponibilizadas de maneiras diferentes. Alguns órgãos disponibilizavam em seus próprios sites, ao passo que outros redirecionavam para o Portal da Transparência, Portal de Convênios, Páginas de Transparência Pública ou para a página do SICONV. Vale salientar que página do SICONV apresenta problemas com seu certificado digital, o que pode dificultar o acesso por pessoas leigas ou menos experientes. $O$ site do Palácio do Planalto redireciona tal requisito para os sites de suas secretarias.

Registro das despesas: esse requisito foi cumprido por 21 dos 23 órgãos pesquisados. Essa informação não foi encontrada no site oficial do Ministério da Indústria, Comércio Exterior e Serviços. No caso do Ministério dos Transportes, Portos e Aviação Civil, alguns links não existiam, não sendo possível consultar tais informações. Observou-se que os demais sites utilizam o Portal da Transparência e as Páginas de Transparência Pública para essa consulta. 0 site do Palácio do Planalto redireciona tal requisito para os sites de suas secretarias.

Execução orçamentária e financeira detalhada: esse requisito foi cumprido por 21 dos 23 órgãos pesquisados. Essa informação não foi encontrada no site oficial do Ministério da Indústria, Comércio Exterior e Serviços. No caso do Ministério dos Transportes, Portos e Aviação Civil alguns links não existiam, não sendo possível consultar tais informações. Observou-se que os demais sites redirecionam a busca para o Portal da Transparência, Páginas de Transparência Pública, Orçamento Federal. No caso do Palácio do Planalto, o redirecionamento é feito para o site da CGU. Recomenda-se que o Ministério dos Transportes, Portos e Aviação Civil procure criar esses links até então inexistentes, para que a população possa fazer sua consulta.

Respostas a perguntas mais frequentes da sociedade: esse requisito foi cumprido por 21 dos 23 órgãos pesquisados. Esse item não foi encontrado nos sites do Palácio do Planalto e do Ministério da Justiça e Segurança Pública.

Telefone do Serviço de Informações ao Cidadão: essa informação foi cumprida por 22 dos 23 órgãos pesquisados. A informação não foi encontrada no site do Ministério da Justiça e 
Segurança Pública, onde constam apenas os telefones de SIC setoriais, como o do Arquivo Nacional e da Defensoria Pública da União.

Formulário para pedido de acesso à informação: esse requisito foi cumprido por 22 dos 23 órgãos pesquisados. No caso do site do Palácio do Planalto - Presidência da República, não foi encontrado nenhum link que levasse ao formulário para pedido de acesso à informação, contudo há um direcionamento para as secretarias, que podem conter esse formulário. Vale lembrar que esse formulário está presente no site <www.acessoainformação.gov.br $>$. Percebese que os órgãos pesquisados disponibilizam dois formulários diferentes, um para pessoa física e outro para pessoa jurídica. O fato de haver dois tipos de formulários é relevante pois, além de facilitar o pedido de informação, auxilia também a criação de um relatório de pedidos de informação que contenha o perfil dos solicitantes, o que pode ser usado para melhorar cada vez mais o atendimento prestado nos SIC.

Atualização das informações disponíveis: esse requisito foi cumprido parcialmente por todos os órgãos pesquisados, exceto o Palácio do Planalto, que não continha documentos, mas redirecionava para os sites de suas secretarias. Percebeu-se que todos os documentos continham ao menos uma não conformidade ou estavam desatualizados. As desatualizações ficaram evidentes, por exemplo, em documentos classificados e desclassificados, bem como em documentos e informações referentes as finanças dos órgãos.

Garantia de autenticidade e integridade das informações disponíveis: percebeu-se que 22 dos 23 órgãos pesquisados não utilizam uma criptografia na conexão (HTTPS) entre o servidor e o dispositivo utilizado pelo cidadão. Isso representa um risco elevado para a segurança das informações fornecidas pelo órgão público, pois a sua ausência pode comprometer a integridade e a autenticidade dos documentos fornecidos. Somente o site do Ministério das Cidades possui este protocolo de criptografia, contudo seu certificado digital está vencido há alguns meses.

Realização de audiências ou consultas públicas, incentivo à participação popular ou a outras formas de divulgação: esse requisito foi cumprido por 11 dos 23 órgãos pesquisados. Houve uma grande dificuldade de encontrar tais informações, devido à falta de um link específico que as forneça. Apesar dessa dificuldade, as mesmas foram identificadas em locais diferentes nos sites oficiais dos seguintes órgãos: MAPA, MC, MEC, MF, MJ, MME, MPOG, MS, MT, MPS, CGU. Nos sites dos demais órgãos (PR, MCTIC, MinC, MDS, MD, MDIC, ME, MIN, MMA, MRE, MTPAC e MTur), não foi encontrado nenhum tipo de informação relativa a realização de audiências, consultas públicas, incentivos à participação popular ou outras formas de divulgação. 
Rol das informações desclassificadas nos últimos doze meses: este requisito foi cumprido por 22 dos 23 órgãos pesquisados. O rol de informações desclassificadas nos últimos 12 meses não foi encontrado no site do Ministério do Esporte. Em 14 dos 23 órgãos, não foram encontradas informação desclassificada nos últimos 12 meses. O restante dos órgãos possuía ao menos uma informação desclassificada nos últimos 12 meses.

Rol das informações classificadas em cada grau de sigilo: esse requisito foi cumprido por 22 dos 23 órgãos. Em relação as informações classificadas, 13 dos 23 órgãos possuíam informações classificadas, sendo eles: MAPA, MCTIC, MD, MDIC, ME, MF, MJ, MME, MPOG, MRE, MS, CGU e MTPAC. O link que continha essas informações no site do Ministério do Trabalho estava inativo, não sendo possível verificar se o mesmo possui ou não informações classificadas como sigilosas. Em relação aos demais órgãos, 9 dos 23 pesquisados não possuíam nenhuma informação classificada.

Categoria na qual se enquadra a informação classificada: esse requisito foi cumprido por 8 dos 13 órgãos que informaram possuir informações classificadas. Cinco órgãos não informaram em seus documentos a categoria na qual se enquadrava a informação classificada: MAPA, MME, MRE, MS e MT.

Indicação de dispositivo legal que fundamenta a classificação: dentre os 13 órgãos que possuíam informações classificadas, esse requisito foi cumprido por 9 órgãos, sendo que 3 órgãos descumpriram e 1 órgão cumpriu parcialmente. A informação não foi encontrada nos documentos nos sites do Ministério das Relações Exteriores, do Ministério da Saúde e do Ministério do Trabalho. Já no site do MAPA, as informações se encontravam desorganizadas, o que dificulta a análise das mesmas, podendo-se considerar como um requisito parcialmente cumprido.

Data da produção da informação classificada: esse requisito foi descumprido por 3 órgãos dos 13 órgãos pesquisados que possuíam informações classificadas, sendo eles o Ministério da Agricultura, Pecuária e Abastecimento, o Ministério das Relações Exteriores e o Ministério do Trabalho. Nesse caso, não foi encontrada a data de produção de nenhum dos documentos disponibilizados.

Data da classificação: esse requisito foi cumprido por 10 órgãos dentre os que possuíam informações classificadas, e descumprido por 3 órgãos, sendo eles o Ministério da Agricultura, Pecuária e Abastecimento, o Ministério das Relações Exteriores e o Ministério do Trabalho. Nesse caso, não foi encontrada a data de classificação nos documentos disponibilizados.

Prazo da classificação: este requisito foi cumprido por 9 órgãos dentro do grupo dos que possuíam informações classificadas e descumprido por quatro órgãos, sendo eles o Ministério 
da Agricultura, Pecuária e Abastecimento, o Ministério de Minas e Energia, o Ministério das Relações Exteriores e o Ministério do Trabalho. Nesses casos, não foi encontrado o prazo de classificação em nenhum dos documentos disponibilizados.

Relatórios estatísticos com a quantidade de pedidos de acesso à informação recebidos, atendidos e indeferidos, além das informações estatísticas agregadas dos requerentes: nesse caso, 7 dos 23 órgãos cumpriram este requisito, uma vez que disponibilizaram em seus sites ou criaram um link que redirecionasse para o local que continha a informação. Em 16 órgãos, esse relatório não constava em seus sites, sendo eles: PR, MAPA, MCTIC, MinC, ME, MF, MIN, MJ, MMA, MME, MRE, MS, MT, MPS, MTPAC e Mtur. Salienta-se, contudo, que os relatórios existem e estão disponíveis no site Acesso à Informação do Governo Federal. Observou-se também que, em alguns casos, a informação se encontrava desatualizada e não oferecia redirecionamento de página, nem a criação de links específicos para acessá-las.

Algumas exigências legais foram inteiramente descumpridas pelos sites dos órgãos pesquisados. O primeiro requisito descumprido integralmente por todos os sites dos órgãos refere-se aos programas financiados pelo FAT (Fundo de Amparo ao Trabalhador). O FAT é um fundo especial vinculado ao Ministério do Trabalho e é destinado ao custeio do Programa do Seguro-Desemprego, do Abono Salarial e ao financiamento de Programas de desenvolvimento econômico (MINISTÉRIO DO TRABALHO, 2015). Durante a investigação, não foram encontradas informações relativas a programas financiados pelo FAT nos sites pesquisados. Recomenda-se que os órgãos públicos criem um link específico contendo as informações relativas a esses programas $^{3}$. Já o segundo requisito descumprido integralmente por todos os sites dos órgãos, refere-se à divulgação em detalhes sobre os formatos utilizados para estruturação das informações divulgadas.

\section{Conclusões}

Ao longo do período de vigência da LAI no Brasil, os órgãos públicos têm descumprido os princípios da legais que regem o acesso à informação pública no país, tanto em nível federal, quanto a nível estadual, municipal, nos três poderes. Diversas pesquisas têm apresentado esse diagnóstico e algumas têm revelado modestas melhorias no cumprimento das diretrizes estabelecidas na LAI e no decreto n. 7.724/2012 (ARTIGO 19, 2013, 2014, 2015, 2017; CAVALCANTI, DAMASCENO, NETO, 2013; GOMES, 2016; GOMES, MARQUES, KERR PINHEIRO,

\footnotetext{
${ }^{3}$ Na ocasião da redação do presente artigo, no ano de 2018, notou-se que o site do Ministério do trabalho já contava com um link específico na sua página principal, que redireciona o cidadão para o portal do Fundo de Amparo ao Trabalhador.
} 
2016; JARDIM, MIRANDA, 2015; MENDES, 2014; SANTOS, NAVARRO, 2016; NASCIMENTO SILVA, KERR PINHEIRO, 2015; VENTURA, FELL, 2012; VIEIRA, 2013).

Por meio da pesquisa ora relatada, foi possível concluir que no ano de 2016 continuou havendo relevante e evidente descumprimento das diretrizes de transparência ativa nos sites dos órgãos do Poder Executivo Federal brasileiro. Os sites dos órgãos e entidades públicas que compuseram o escopo da pesquisa descumpriram diversas exigências legais, como, por exemplo, informações relativas a competências, horários de atendimento ao público, estrutura organizacional, programas financiados pelo Fundo de Amparo ao Trabalhado, relatórios estatísticos com a quantidade de pedidos de acesso à informação recebidos, rol das informações desclassificadas nos últimos doze meses, rol das informações classificadas em cada grau de sigilo, dentre outras informações. Observou-se que alguns itens foram cumpridos parcialmente e outros foram totalmente descumpridas por esses órgãos.

Percebe-se, portanto, que os descumprimentos da legislação revelados pela pesquisa devem ser corrigidos pelos órgãos públicos em tela, para que seus websites passem a atender plenamente os ditames da LAI e do decreto n. 7.724/2012. Nesse sentido, o trabalho apontou não conformidades relativas a transparência ativa a serem sanadas nos sites dos órgãos investigados. Espera-se, assim, que cada vez mais se amplie o acesso e o controle social da informação pública custodiada palas instituições que compõem o Estado brasileiro. Essa é demanda é imprescindível para que a sociedade civil assuma papel de protagonista no acompanhamento, gestão e intervenção em ações e políticas públicas. Superar a cultura de sigilo que ainda vigora em diferentes órgãos públicos, bem como eliminar o descumprimento dos preceitos legais que regem o acesso à informação pública, são pré-condições para que esse protagonismo seja possível.

Como perspectivas de pesquisas futuras, nota-se que as investigações sobre o cumprimento da LAI e o Decreto n. 7.724/2012 devem ser contínuas e periódicas. Recomendase a realização de pesquisas com periodicidade anual, de modo a prover diagnósticos regulares sobre a evolução desse quadro. Adicionalmente, recomenda-se a realização de novas pesquisas que abarquem os níveis estaduais e municipais, assim como os poderes legislativo e judiciário, o que permitirá uma visão mais ampla das três esferas que compõem o Estado brasileiro.

\section{Referências}

ARTIGO 19. Balanço de 1 ano da lei de acesso à informação pública. São Paulo: Artigo 19. 2013. Disponível em: <http://artigo19.org/blog/2013/05/24/balanco-de-1-ano-da-lei-deacesso-a-informacao-publica >. Acesso em: 24 abr. 2018. 
ARTIGO 19. Monitoramento da Lei de Acesso à Informação Pública em 2013. São Paulo: Artigo 19. 2014. Disponível em: <http://artigo19.org/wp-

content/uploads/2014/05/Relat\%C3\%B3rio-Monitoramento-LAl-2013.pdf>. Acesso em: 24 abr. 2018.

ARTIGO 19. Monitoramento da Lei de Acesso à Informação Pública em 2014. São Paulo:

Artigo19. 2015. Disponível em: <http://artigo19.org/wp-

content/uploads/2015/05/Monitoramento-da-Lei-de-Acesso-\%C3\%80-

Informa\%C3\%A7\%C3\%A3o-P\%C3\%BAblica-em-2014.pdf>. Acesso em: 24 abr. 2018.

ARTIGO 19. Os 5 anos da Lei de Acesso à Informação uma análise de casos de transparência. São Paulo: Artigo 19. 2017. Disponível em: <http://artigo19.org/wp-

content/blogs.dir/24/files/2017/05/Os-5-anos-da-Lei-de-Acesso-à-Informação---uma-análisede-casos-de-transparência.pdf>. Acesso em: 24 abr. 2018.

BRASIL. Lei no 12.527, de 18 de novembro de 2011. 2011. Disponível em: <http://www.planalto.gov.br/ccivil 03/ ato2011-2014/2011/lei/l12527.htm>. Acesso em: 15 set. 2016.

BRASIL. Decreto no 7.724, de 16 de maio de 2012. 2012. Disponível em: <http://www.planalto.gov.br/ccivil 03/ ato2011-2014/2012/decreto/d7724.htm>. Acesso em: 24 abr. 2018.

BRASIL, Decreto no 9.003, de 13 de março de 2017. 2017. Disponível em:

$<$ http://www2.camara.leg.br/legin/fed/decret/2017/decreto-9003-13-marco-2017-784449normaatualizada-pe.html> Acesso em: 24 abr. 2018.

BRASIL. MINISTÉRIO DO TRABALHO. Fundo de Amparo ao Trabalhador - FAT. 2015. Disponível em: <http://portalfat.mte.gov.br/codefat/resolucoes-2/resolucoes-por-assunto/geracao-deemprego-e-renda/linhas-de-creditos-especiais/fat-giro-cooperativo-agropecuario/sobre-ofat>. Acesso em: 16 fev. 2018.

CAVALCANTI, Joyce Mariella Medeiros; DAMASCENO, Larissa Mayara da Silva; NETO, Manoel Veras de Souza. Observância da lei de acesso à informação pelas autarquias federais do Brasil. Perspectiva em Ciência da Informação, v. 18, n. 4, 2013.

CEPIK, Marco. Direito à Informação: Situação Legal e Desafios. Informática Pública, Belo Horizonte, v. 2, n. 2, 2000.

GOMES, Simone Regina Luiz. Implementação da Lei de Acesso à Informação Pública no IFMG: Impactos e Desafios. 2016. Dissertação (Mestrado em Sistemas de Informação e Gestão do Conhecimento), Universidade FUMEC, Belo Horizonte, 2016.

GOMES, Simone Regina Luiz; MARQUES, Rodrigo Moreno; KERR PINHEIRO, Marta Macedo. A cultura organizacional e os desafios da Lei de Acesso à Informação nas instituições públicas brasileiras. Revista Ágora: políticas públicas, comunicação e governança informacional, v. 1, n. 1,2016 
GRUMAN, Marcelo. Lei de Acesso à Informação: notas e um breve exemplo. Revista Debates, v. 6, n. 3, p. 97-108, set./dez. 2012. Disponível em:

<http://seer.ufrgs.br/debates/article/view/34229/23345>. Acesso em: 16 fev. 2018.

JARDIM, José Maria; MIRANDA, Vanessa Leite. A implantação da lei de acesso a informação nas universidades federais do estado de Rio de Janeiro. In: XVI Encontro Nacional de Pesquisa em Ciência da Informação (XVI ENANCIB), 2015, João Pessoa. Anais... João Pessoa: UFPB, 2015.

MEIRELLES, Hely Lopes. Direito administrativo brasileiro. São Paulo: Malheiros, 2005. MENDES, Rodrigo Braga. Impacto da Lei de Acesso à Informação: os casos da Agência Nacional de Petróleo, Gás Natural e Biocombustível e das Agências Reguladoras Federais. Rio de Janeiro: FGV, 2014.

SÁ, Maria Irene da Fonseca; MALIN, Ana Maria Barcelos. Lei de Acesso à Informação: Um Estudo Comparativo com Outros Países. In: XIII Encontro Nacional de Pesquisa em Ciência da Informação (XIII ENANCIB), 2012, Rio de Janeiro. Anais... Rio de Janeiro: ANCIB. 2012.

SANTOS, Gabriela; NAVARRO, Maria Teresa. Análise da lei de acesso a informação nos sítios das secretarias da fazenda dos estados brasileiros e do distrito federal. In: XVII Encontro Nacional de Pesquisa em Ciência da Informação (XVII ENANCIB), 2016, Salvador. Anais... Salvador: ANCIB, 2016.

NASCIMENTO SILVA, Patrícia; KERR PINHEIRO, Marta Macedo. Dados governamentais abertos e lei de acesso à informação: diagnóstico nas universidades públicas federais brasileiras. In: XVI Encontro Nacional de Pesquisa em Ciência da Informação (XVI ENANCIB), 2015, João Pessoa.

Anais... João Pessoa: ANCIB, 2015.

VENTURA, Kátia Santiago; FELL, André Felipe de Albuquerque. Acesso à informação pública de qualidade: estudo da aplicação da lei no 12.527/2011 pelas instituições federais de ensino superior da região nordeste. In: XIII Encontro Nacional de Pesquisa em Ciência da Informação (XIII ENANCIB), 2012, Rio de Janeiro. Anais... Rio de Janeiro: ANCIB, 2012.

VIEIRA, Vânia Lúcia Ribeiro. Efeitos da Lei de Acesso à Informação (lei no 12.527/2011) nas compras públicas. In: VI Congresso CONSAD de Gestão Pública, 2013, Brasília. Anais do VI Congresso CONSAD de Gestão Pública. Brasília: CONSAD. 2013.

YAZIGI, Alejandro Ferreiro. Dinero, política y transparencia: El imperativo democrático de combatir la corrupción. 9th International Anti-Corruption Conference, 1999, Durban. Anais... Durban: IACC, 1999.

ZUCCOLOTTO, Robson; TEIXEIRA, Marco Antônio Carvalho; RICCIO, Edson Luiz. Transparência: reposicionando o debate. Revista Contemporânea de Contabilidade. UFSC, Florianópolis, v. 12, n. 25, 2015.

\section{Agradecimentos}

A pesquisa contou com financiamento da FUNADESP - Fundação Nacional de Desenvolvimento do Ensino Superior Particular, da Universidade FUMEC (ProPIC 2017/2018) e da FAPEMIG Fundação de Amparo à Pesquisa de Minas Gerais (APQ-02058-17). 